\title{
Low psoas muscle index is a poor prognostic factor for lower gastrointestinal perforation: a single-center retrospective cohort study
}

Hajime Kayano ${ }^{1 *}$ D, Eiji Nomura ${ }^{1}$, Rin Abe ${ }^{1}$, Yasuhiko Ueda', Takashi Machida ${ }^{1}$, Chikara Fujita², Shohei Uchiyama², Kazuyuki Endo ${ }^{2}$, Katsuki Murakami ${ }^{2}$, Masaya Mukai ${ }^{1}$ and Hiroyasu Makuuchi ${ }^{1}$

\begin{abstract}
Background: Various body composition indices have been reported as prognostic factors for different cancers. However, whether body composition affects prognosis after lower gastrointestinal tract perforation requiring emergency surgery and multidisciplinary treatment has not been clarified. This study examined whether body composition evaluations that can be measured easily and quickly from computed tomography (CT) are useful for predicting prognosis.
\end{abstract}

Methods: Subjects comprised 64 patients diagnosed with perforation at final diagnosis after emergency surgery for a preoperative diagnosis of lower gastrointestinal tract perforation and penetration. They were divided into a survival group and a non-survival (in-hospital mortality) group and compared. Body composition indices (psoas muscle index (PMI); psoas muscle attenuation (PMA); subcutaneous adipose tissue index (SATI); visceral adipose tissue index (VATI); visceral-to-subcutaneous fat area ratio (VSR)) were measured from preoperative CT. Crosssectional psoas muscle area at the level of the 3rd lumbar vertebra was quantified. Optimal cut-off values were calculated using receiver operating characteristic curve analysis. Poor prognostic factors were investigated from multivariate logistic regression analyses that included patient factors, perioperative factors, intraoperative factors, and body composition indices as explanatory variables.

Results: The cause of perforation was malignant disease in 12 cases (18.7\%), and benign disease in 52 cases (81.2\%). The most common cause was diverticulum of the large intestine. Emergency surgery for the 64 patients led to survival in 52 patients and death in 12 patients. On multivariate logistic regression analysis, independent predictors of poor prognosis were Sequential Organ Failure Assessment score (odds ratio 1.908; 95\% confidence interval $(\mathrm{Cl}) 1.235-3.681 ; P=0.0020$ ) and PMI (odds ratio 13.478; 95\%Cl 1.342-332.690; $P=0.0252$ ). The cut-off PMl was $4.75 \mathrm{~cm}^{2} / \mathrm{m}^{2}$ for males and $2.89 \mathrm{~cm}^{2} / \mathrm{m}^{2}$ for females. Among survivors, duration of hospitalization was significantly longer in the low PMI group (29 days) than in the high PMI group (22 days, $p=0.0257$ ).

Conclusions: PMI is easily determined from $C T$ and allows rapid evaluation of prognosis following lower gastrointestinal perforation.

Keywords: Lower gastrointestinal perforation, Body composition, Psoas muscle index, Poor prognosis

\footnotetext{
* Correspondence: h.kayano@tsc.u-tokai.ac.jp

${ }^{1}$ Departments of General and Gastroenterological Surgery, Tokai University

Hachioji Hospital, 1838 Ishikawa-machi, Hachioji, Tokyo 192-0032, Japan

Full list of author information is available at the end of the article
}

(c) The Author(s). 2019 Open Access This article is distributed under the terms of the Creative Commons Attribution 4.0 International License (http://creativecommons.org/licenses/by/4.0/), which permits unrestricted use, distribution, and reproduction in any medium, provided you give appropriate credit to the original author(s) and the source, provide a link to the Creative Commons license, and indicate if changes were made. The Creative Commons Public Domain Dedication waiver (http://creativecommons.org/publicdomain/zero/1.0/) applies to the data made available in this article, unless otherwise stated. 


\section{Background}

Perforation of the lower gastrointestinal tract is a pathological condition that can easily result in severe bacterial infection and subsequent septic shock due to fecal peritonitis. As this condition increases in severity, disseminated intravascular coagulation (DIC) can arise and easily fall into multiple organ failure, sometimes leading to death. The basic principle of treatment is abdominal lavage and drainage with emergency surgery, focal excision, or colostomy. Furthermore, intensive treatment including blood purification therapies such as polymyxin$\mathrm{B}$ direct hemoperfusion (PMX-DHP) and continuous hemodiafiltration (CHDF) is required after surgery, but the mortality rate remains high despite progress in surgical techniques and postoperative management $[1,2]$. The ability to predict the prognosis before surgery would allow for more thorough and proactive perioperative management. Prediction of postoperative complications using various evaluations of body composition has recently been reported in gastrointestinal cancer surgery [3-5]. Further, sarcopenia has been reported as an important prognostic factor after abdominal surgery, including liver transplantation [6, 7]. However, with lower gastrointestinal tract perforation, very few studies have examined the influence of body components such as skeletal muscle mass or fat mass on prognosis. The purpose of this study was therefore to clarify whether somatic composition affects the prognosis of lower gastrointestinal perforation.

\section{Methods}

\section{Study design}

This retrospective cohort study was conducted at Tokai University Hachioji Hospital after being approved by the Institutional Review Board for Clinical Research at Tokai University. A total of 83 patients were diagnosed with perforation and penetration of the lower gastrointestinal tract from May 2010 to March 2019 and were treated with emergency surgery. Two cases for which abdominal computed tomography (CT) was not performed before surgery were excluded from this study. A further 17 cases in which the patient was diagnosed with lower digestive tract penetration from both preoperative abdominal CT and intraoperative findings were excluded from this study because they did not have panperitonitis and may not always be indicated for surgery. The remaining 64 cases were divided into a survival group and a nonsurvival (in-hospital mortality) group and analyzed.

\section{Data collection}

Patient factors, preoperative factors, intraoperative factors, and postoperative courses are managed in a database. CT examinations performed preoperatively are stored in electronic medical records. Data from these sources were accessed for this study.

\section{Patient and perioperative factors}

Patient factors included age, sex, preoperative comorbidities, and body mass index (BMI). Preoperative factors included white blood cell count, C-reactive protein (CRP) concentration, albumin value, time from onset to surgery, Acute Physiology and Chronic Health Evaluation (APACHE) II score [8], and Sequential Organ Failure Assessment (SOFA) score [9]. Intraoperative factors included operative time, blood loss, presence or absence of blood transfusion, cause of perforation, site of perforation, and operation method.

\section{Body component analysis measurement}

Abdominal CT images used in the diagnosis of lower gastrointestinal perforation before surgery were used to evaluate body composition. Abdominal CT was performed using an Aquilion $\mathrm{ONE}^{\mathrm{m} M}$ platform (Canon Medical Systems, Tochigi, Japan). Psoas muscle mass, CT attenuation value of the psoas muscle, visceral fat area, and subcutaneous fat area were analyzed using a Ziostation2 Plus general-purpose diagnostic imaging workstation (Ziosoft, Tokyo, Japan). Each component was measured from horizontal cross-sections of the abdominal CT images. Psoas muscle area was traced as the region of interest (ROI) of the iliopsoas muscle contour at the level of the third lumbar vertebra (L3) (Fig. 1), and the sum of left and right areas was calculated. This area was then standardized as the psoas muscle index (PMI; in $\mathrm{cm}^{2} / \mathrm{m}^{2}$ ) by dividing the value by the square of height in meters. In addition, the $\mathrm{CT}$ attenuation value of the psoas muscle traced as described above was obtained to represent the variable of fat accumulation in psoas muscle that characterizes muscle atrophy, and the average of values for left and right muscles was taken as psoas muscle attenuation (PMA; in Hounsfield units). In the same manner, the areas of subcutaneous fat and visceral fat were calculated by measuring abdominal fat mass using the horizontal cross-section at the L3 level, and each area was then divided by the square of height

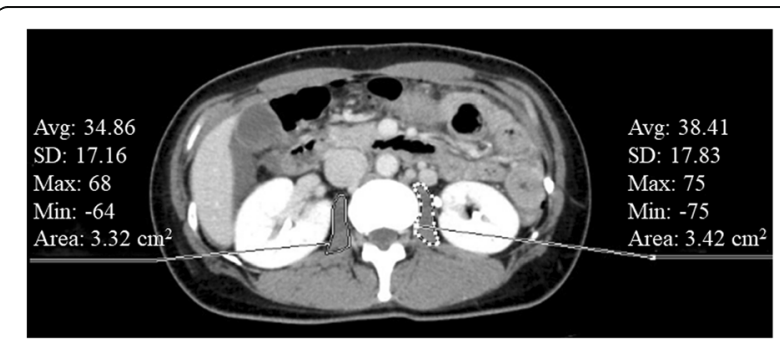

Fig. 1 PMI measurement. Body muscle mass measured using axial $\mathrm{CT}$ imaging at the level of the third lumbar vertebra (L3) 
in meters. With these standardizations, subcutaneous adipose tissue index (SATI; in $\mathrm{cm}^{2} / \mathrm{m}^{2}$ ) and visceral adipose tissue index (VATI; in $\mathrm{cm}^{2} / \mathrm{m}^{2}$ ) were determined, respectively. In addition, visceral-to-subcutaneous fat area ratio (VSR) was calculated as the visceral fat area divided by the subcutaneous fat area as an index of abdominal fat distribution. The receiver operating characteristic (ROC) curve was plotted for each variable, the optimal cut-off value for death due to lower gastrointestinal perforation was obtained via the Youden Index, and participants were assigned to the low-value or highvalue group accordingly.

\section{Postoperative multidisciplinary treatment}

Postoperative multidisciplinary treatment was evaluated by the presence or absence of ventilatory management, blood purification (PMX-DHP), recombinant human soluble thrombomodulin (rTM) (Asahi Kasei Pharma Corporation, Tokyo, Japan), human anti-thrombin III, freeze-dried concentrated (hATIII) (Japan Blood Products Organization, Tokyo, Japan), and intravenous immunoglobulin (IVIg) (freeze-dried sulfonated human normal immunoglobulin; Teijin Pharma, Tokyo, Japan).

\section{Outcome data}

Data reflecting the postoperative course included DIC score on postoperative day 1 , presence or absence of DIC on postoperative day 1, length of stay (LOS) in the intensive care unit (ICU) in days, duration until withdrawal of ventilatory support in days, postoperative complications, and postoperative stay in days. All postoperative complications were classified using the Clavien-Dindo classification (CD) [10], with CD3 or above defined as postoperative complications for the purposes of this study.

\section{Statistical analysis}

In the statistical analyses, comparisons between two groups were made using the Mann-Whitney test for continuous variables and either a $X^{2}$ test or Fisher's exact test (for any test involving a low number of samples) for categorical variables, with values of $p<0.05$ regarded as significant. The determination of each cut-off was determined from the maximal Youden index for the ROC curve. Separate determinations were made for males and females, as muscle mass is significantly greater in males than in females regardless of age [11]. To identify prognostic factors, univariate analysis was performed first, followed by multivariate analysis using all significant variables from univariate analysis. On univariate analysis, the Mann-Whitney test was used for continuous variables, and the Pearson $x^{2}$ test for categorical variables. Multivariate analysis was performed using logistic regression. The software used for all statistical analyses was JMP for Windows version 13.0 (SAS Institute, Cary, $\mathrm{NC}$.

\section{Results \\ Patient characteristics}

The 64 patients included more females than males, with a median age of 72 years (Table 1). Preoperative comorbidities were noted in 47 cases (73.4\%), with hypertension as the most common, followed by heart disease and cerebrovascular disease. Median APACHE II score and SOFA score on admission to the ICU were 11 and 4, respectively. Median time from onset to surgery was $10 \mathrm{~h}$, median operative time was $148 \mathrm{~min}$, and median blood loss was $244 \mathrm{ml}$, with blood transfusion performed in $37.5 \%$ of cases. In terms of body composition, PMI, VAR, and PMA were higher in males than in females, but SATI and VATI were higher in females than in males (Table 1). The cause of perforation was malignant disease in 12 cases $(18.7 \%$ ) and benign disease in 52 cases $(81.2 \%)$. The most common cause of perforation was diverticulum of the large intestine, followed by iatrogenic perforation. The site of perforation involved the right colon in 10 cases and the left colon in 54 cases, with the sigmoid colon accounting for 36 cases (56.2\%). More than half of the cases (51.6\%) underwent the Hartmann operation, followed by colon colostomy only.

\section{Cut-off values and AUCs for body composition}

Cut-off values and AUCs for body composition are shown in Table 2. Males showed higher cut-off values than females for all variables. The PMI for males was the highest AUC among males at 0.72. The PMI for females was 0.63 , the second-highest AUC among females.

\section{Prognostic factors}

In examining for prognostic factors (Table 3), no significant differences between the survival group and nonsurvival group were seen in patient factors. Among preoperative factors, platelet count $\left(15.35 \times 10^{4} / \mu \mathrm{l}\right.$ vs. $\left.22.45 \times 10^{4} / \mu \mathrm{l} ; P=0.0040\right)$ and albumin levels $(2.4 \mathrm{mg} / \mathrm{dl}$ vs. $3.0 \mathrm{mg} / \mathrm{dl} ; P=0.0082$ ) were significantly lower in the non-survival group compared to the survival group. In addition, the non-survival group showed significantly higher APACHE II score (17 vs $10 ; P=0.0007)$ and SOFA score (9 vs $3 ; P=0.0001$ ) than the survival group. No significant differences between groups were seen among intraoperative factors. Among body composition indices, the non-survival group showed significantly higher frequencies of low PMI $(75 \%$ vs $40.38 \% ; P=$ $0.0303)$ and low VAR ( $86.54 \%$ vs $58.33 \% ; P=0.0240)$ compared to the survival group. Using each factor that showed significant differences from univariate analyses, multivariate logistic regression analysis identified SOFA score (odds ratio 1.908, 95\% confidence interval (CI) 
Table 1 Baseline characteristics

\begin{tabular}{|c|c|}
\hline Characteristic & $n=64$ \\
\hline \multicolumn{2}{|l|}{ Patient characteristics } \\
\hline Age (years) ${ }^{a}$ & $72(46-101)$ \\
\hline Sex, male/female, n (\%) & 25 (39.0) / 39 (60.9) \\
\hline BMI $\left(\mathrm{kg} / \mathrm{m}^{2}\right)^{\mathrm{a}}$ & $21.2(13.5-36.0)$ \\
\hline Comorbidities, n (\%) & 47 (73.4) \\
\hline Hypertension & $33(51.5)$ \\
\hline Heart disease & $24(37.5)$ \\
\hline Diabetes mellitus & $10(15.6)$ \\
\hline Cerebrovascular disease & $10(15.6)$ \\
\hline Renal disease & $9(14.0)$ \\
\hline Lung disease & $6(9.3)$ \\
\hline Collagen disease & $5(7.8)$ \\
\hline Mental disease & $3(4.6)$ \\
\hline \multicolumn{2}{|l|}{ Perioperative characteristics } \\
\hline White blood cells $(/ \mu l)^{\mathrm{a}}$ & $8000(900-509,000)$ \\
\hline C-reactive protein $(\mathrm{mg} / \mathrm{dl})^{\mathrm{a}}$ & $4.8(0.01-40.9)$ \\
\hline Platelet $\left(\times 10^{4} / \mu \mathrm{l}\right)^{\mathrm{a}}$ & $21.7(3.9-75.4)$ \\
\hline Albumin $(\mathrm{mg} / \mathrm{dll})^{\mathrm{a}}$ & $2.9(1.6-4.7)$ \\
\hline APACHE II score ${ }^{a}$ & $11(2-22)$ \\
\hline SOFA score ${ }^{a}$ & $4(0-14)$ \\
\hline $\begin{array}{l}\text { Interval from onset to surgery } \\
(\text { h) }\end{array}$ & $10(2-200)$ \\
\hline \multicolumn{2}{|l|}{ Intraoperative factor } \\
\hline \multicolumn{2}{|l|}{ Primary disease, n (\%) } \\
\hline Diverticulosis & $26(40.6)$ \\
\hline latrogenic & $13(20.3)$ \\
\hline Cancer & $12(18.7)$ \\
\hline Fecal impaction & $8(12.5)$ \\
\hline Ischemic & $5(7.8)$ \\
\hline \multicolumn{2}{|l|}{ Site of perforation, n (\%) } \\
\hline Sigmoid & $36(56.2)$ \\
\hline Rectum & $10(15.6)$ \\
\hline Descending & $8(12.5)$ \\
\hline Ascending & $6(9.3)$ \\
\hline Transverse & $2(3.1)$ \\
\hline Cecum & $2(3.1)$ \\
\hline \multicolumn{2}{|l|}{ Surgical procedure, n (\%) } \\
\hline Hartmann operation & $33(51.5)$ \\
\hline Colostomy & $10(15.6)$ \\
\hline Resection with ileostomy & $6(9.3)$ \\
\hline Resection with colostomy & $5(7.8)$ \\
\hline Simple closure with colostomy & $5(7.8)$ \\
\hline Resection & $3(4.6)$ \\
\hline Simple closure with ileostomy & $2(3.1)$ \\
\hline
\end{tabular}

Table 1 Baseline characteristics (Continued)

\begin{tabular}{ll}
\hline Characteristic & $n=64$ \\
\hline Operative time (min) & $148(30-336)$ \\
Blood loss (ml) & $244(5-4100)$ \\
Transfusion (\%), $n(\%)$ & $24(37.5)$ \\
Body composition variables & \\
PMI $\left(\mathrm{cm}^{2} / \mathrm{m}^{2}\right)$ & $3.60(1.42-7.02)$ \\
Male/Female & $4.44(1.59-6.81) / 3.09(1.42-7.02)$ \\
SATI $\left(\mathrm{cm}^{2} / \mathrm{m}^{2}\right)$ & $32.72(0.01-136.09)$ \\
Male/Female & $22.48(0.34-105.37) / 47.27(0.01-$ \\
& $136.09)$ \\
VATI (cm $\left.2 / \mathrm{m}^{2}\right)$ & $22.64(0.53-112.77)$ \\
Male/Female & $21.95(1.83-98.06) / 23.33(0.53-$ \\
VSR & $112.77)$ \\
Male/Female & $0.73(0.14-5.04)$ \\
PMA (HU) & $0.75(0.32-7.31) / 0.59(0.14-5.04)$ \\
Male/Female & $37.78(-22.92-66.76)$ \\
& $44.30(18.90-66.76) / 34.41(-22.92-$ \\
\end{tabular}

BMI body mass index $\left(\mathrm{kg} / \mathrm{m}^{2}\right)$, APACHE II Acute Physiology and Chronic Health Evaluation II, SOFA Sequential Organ Failure Assessment, $P M I$ psoas muscle index $\left(\mathrm{cm}^{2} / \mathrm{m}^{2}\right)$, SATI subcutaneous adipose tissue index $\left(\mathrm{cm}^{2} / \mathrm{m}^{2}\right)$, VATI visceral adipose tissue index $\left(\mathrm{cm}^{2} / \mathrm{m}^{2}\right)$, VSR visceral-to-subcutaneous fat area ratio, PMA psoas muscle attenuation (HU), HU Hounsfield units

${ }^{a}$ Values are shown as median (range)

1.235-3.681, $P=0.0020$ ) and PMI (odds ratio 13.478, 95\% CI $1.342-332.690, P=0.0252$ ) as independently associated with poor prognosis.

\section{Influence of PMI on survival cases}

In comparing the postoperative course and postoperative multidisciplinary treatment in the high and low PMI subgroups within the survival group, hospitalization was significantly longer in the low PMI subgroup (29 days) than in the high PMI subgroup (22 days, $p=0.0257$ ) (Table 4). DIC score, DIC rate, postoperative complication rate, and LOS in the ICU all tended to be higher in the low PMI subgroup than in the high PMI subgroup. However, no difference in postoperative multidisciplinary treatment was found between the two subgroups (Table 5).

Table 2 Cut-off values and AUC for body composition

\begin{tabular}{|c|c|c|c|c|c|c|}
\hline & & $\begin{array}{l}\mathrm{PMl} \\
\left(\mathrm{cm}^{2} / \mathrm{m}^{2}\right)\end{array}$ & $\begin{array}{l}\text { SATI } \\
\left(\mathrm{cm}^{2} / \mathrm{m}^{2}\right)\end{array}$ & $\begin{array}{l}\text { VATI } \\
\left(\mathrm{cm}^{2} / \mathrm{m}^{2}\right)\end{array}$ & VAR & $\begin{array}{l}\text { PMA } \\
(\mathrm{HU})\end{array}$ \\
\hline \multirow[t]{2}{*}{ Men } & Cut-off & 4.75 & 25.98 & 36.95 & 3.05 & 37.57 \\
\hline & AUC & 0.72 & 0.56 & 0.57 & 0.59 & 0.67 \\
\hline \multirow[t]{2}{*}{ Female } & Cut-off & 2.89 & 0.27 & 8.79 & 1.24 & 32.86 \\
\hline & AUC & 0.63 & 0.62 & 0.57 & 0.68 & 0.56 \\
\hline
\end{tabular}

$A \cup C$ area under the curve 
Table 3 Uni- and multivariate analysis of factors predicting using logistic regression

\begin{tabular}{|c|c|c|c|c|c|c|}
\hline & \multicolumn{3}{|l|}{ Univariate analysis } & \multicolumn{3}{|c|}{ Multivariate analysis } \\
\hline & Survival $(n=52)$ & Non-survival $(n=12)$ & $P$-value & Odds ratio & $95 \% \mathrm{Cl}$ & $P$-value \\
\hline \multicolumn{7}{|l|}{ Patient factors } \\
\hline Age (years) ${ }^{a}$ & $72(46-101)$ & $74(60-87)$ & 0.8029 & & & \\
\hline Sex, male/female, n (\%) & 18 (34.6) / 34 (65.3) & $7(58.3) / 5(41.6)$ & 0.1290 & & & \\
\hline BMI $\left(\mathrm{kg} / \mathrm{m}^{2}\right)^{\mathrm{a}}$ & $21.6(13.5-36.0)$ & $20.4(15.2-25.6)$ & 0.2563 & & & \\
\hline Comorbidities, n (\%) & $36(69.2)$ & $11(91.6)$ & 0.1127 & & & \\
\hline Hypertension & $25(48.0)$ & $8(66.6)$ & & & & \\
\hline Heart disease & $19(36.5)$ & $5(41.6)$ & & & & \\
\hline Diabetes mellitus & $8(15.3)$ & $2(16.6)$ & & & & \\
\hline Cerebrovascular disease & $6(11.5)$ & $4(33.3)$ & & & & \\
\hline Collagen disease & $5(9.6)$ & $0(0)$ & & & & \\
\hline Renal disease & $5(9.6)$ & $4(33.3)$ & & & & \\
\hline Lung disease & $4(7.6)$ & $2(16.6)$ & & & & \\
\hline Mental disease & $1(1.9)$ & $2(16.6)$ & & & & \\
\hline \multicolumn{7}{|l|}{ Perioperative factors } \\
\hline White blood cells $(/ \mu l)^{\mathrm{a}}$ & $8550(900-50,900)$ & $3450(1200-40,600)$ & 0.3311 & & & \\
\hline C-reactive protein $(\mathrm{mg} / \mathrm{dl})^{\mathrm{a}}$ & $4.6(0.01-40.9)$ & $13.3(0.1-32.2)$ & 0.3620 & & & \\
\hline Platelets $\left(\times 10^{4} / \mu l\right)^{a}$ & $22.4(9.6-75.4)$ & $15.3(3.9-32.2)$ & $0.0040^{*}$ & 0.898 & $0.771-1.012$ & 0.0831 \\
\hline Albumin $(\mathrm{mg} / \mathrm{dl})^{\mathrm{a}}$ & $3.0(1.6-4.7)$ & $2.4(1.7-3.6)$ & $0.0082^{*}$ & 0.495 & $0.179-33.052$ & 0.5716 \\
\hline APACHE II score ${ }^{a}$ & $10(2-22)$ & $17(5-21)$ & $0.0007^{*}$ & 1.114 & $0.864-1.466$ & 0.6986 \\
\hline SOFA score ${ }^{a}$ & $3(0-10)$ & $9(5-14)$ & $0.0001^{*}$ & 1.908 & $1.235-3.681$ & $0.0020^{*}$ \\
\hline Interval from onset to surgery $(h)^{a}$ & $10(3-140)$ & $8(2-200)$ & 0.1961 & & & \\
\hline \multicolumn{7}{|l|}{ Intraoperative factors } \\
\hline Primary disease, $\mathrm{n}(\%)$ & & & 0.0764 & & & \\
\hline Diverticulosis & $23(44.2)$ & $3(25.0)$ & & & & \\
\hline latrogenic & $11(21.1)$ & $2(16.6)$ & & & & \\
\hline Cancer & $11(21.1)$ & $1(8.3)$ & & & & \\
\hline Fecal impaction & $4(7.6)$ & $4(33.3)$ & & & & \\
\hline Ischemic & $3(5.7)$ & $2(16.6)$ & & & & \\
\hline Site of perforation, n (\%) & & & 0.3245 & & & \\
\hline Sigmoid & $32(61.5)$ & $4(33.3)$ & & & & \\
\hline Rectum & $8(15.3)$ & $2(16.6)$ & & & & \\
\hline Descending & $5(9.6)$ & $3(25.0)$ & & & & \\
\hline Ascending & $5(9.6)$ & $1(8.3)$ & & & & \\
\hline Transverse & $1(1.9)$ & $1(8.3)$ & & & & \\
\hline Cecum & $1(1.9)$ & $1(8.3)$ & & & & \\
\hline Operative time $(\mathrm{min})^{\mathrm{a}}$ & $148(30-287)$ & $136(82-336)$ & 0.7660 & & & \\
\hline Blood loss $(m l)^{a}$ & $215(5-4100)$ & $500(5-3130)$ & 0.3160 & & & \\
\hline Transfusion, n (\%) & $17(32.6)$ & $7(58.3)$ & 0.0982 & & & \\
\hline Surgical procedure, n (\%) & & & 0.4791 & & & \\
\hline Hartmann's & $27(51.9)$ & $6(50.0)$ & & & & \\
\hline Colostomy & $9(17.3)$ & $1(8.3)$ & & & & \\
\hline Resection with colostomy & $4(7.6)$ & $1(8.3)$ & & & & \\
\hline Simple closure with colostomy & $4(7.6)$ & $1(8.3)$ & & & & \\
\hline
\end{tabular}


Table 3 Uni- and multivariate analysis of factors predicting using logistic regression (Continued)

\begin{tabular}{|c|c|c|c|c|c|c|}
\hline & \multicolumn{3}{|c|}{ Univariate analysis } & \multicolumn{3}{|c|}{ Multivariate analysis } \\
\hline & Survival $(n=52)$ & Non-survival $(n=12)$ & $P$-value & Odds ratio & $95 \% \mathrm{Cl}$ & $P$-value \\
\hline Resection with ileostomy & $3(5.7)$ & $3(25.0)$ & & & & \\
\hline Resection & $3(5.77)$ & $0(0)$ & & & & \\
\hline Simple closure with ileostomy & $2(3.8)$ & $0(0)$ & & & & \\
\hline \multicolumn{7}{|l|}{ Body composition variable } \\
\hline Low PMI, n (\%) & $21(40.38)$ & $9(75.0)$ & $0.0303^{*}$ & 13.478 & $1.342-332.690$ & $0.0252^{*}$ \\
\hline Low VATI, n (\%) & 19 (36.54) & $7(58.33)$ & 0.1658 & & & \\
\hline Low SATI, n (\%) & $10(19.23)$ & $5(41.67)$ & 0.0982 & & & \\
\hline Low VSR, n (\%) & $45(86.54)$ & $7(58.33)$ & $0.0240^{*}$ & 3.5075 & $0.190-83.333$ & 0.3925 \\
\hline Low PMA, n (\%) & $15(28.85)$ & $5(41.67)$ & 0.3878 & & & \\
\hline
\end{tabular}

${ }^{*} P<0.05$

$\mathrm{Cl}$ confidence interval

aalues are shown as median (range)

\section{Discussion}

The mortality rate for lower gastrointestinal perforation has been reported as $15.5-26.6 \%[1,2,12]$, similar to the rate in this study. This is probably largely attributable to the presence of numerous Gram-negative bacilli in the large intestine, so bacteremia easily arises following perforation of the lower gastrointestinal tract, and chemical transmitters such as interleukin (IL)-6 are induced, resulting in rapid onset of septic shock. This is considered to lead to multiple organ failure and acute circulatory failure. In abdominal emergencies requiring surgery, the frequency of lower gastrointestinal perforation is not particularly high $[13,14]$. Identification of prognostic factors to improve survival rates for this pathology has long been a priority, due to the high mortality rate [1517]. In addition, the severity of lower gastrointestinal perforation is considered to involve a large number of prognostic factors, and a scoring system is considered important for judging the preoperative condition more comprehensively. Methods for evaluating prognosis in patients with severe disease in general include APACHE II, the Simplified Acute Physiology Score III [18], and the Mortality Prediction Model 0 III [19] as overall evaluations of systemic severity, and multiple organ dysfunction score [20] and SOFA as an evaluation of multiple organ failure. The present study also showed significant differences in APACHE II from univariate analysis, and SOFA was an independent prognostic factor, confirming its usefulness as a severity assessment method. Moreover, Physiological and Operative Severity Score for Mortality and Morbidity (POSSUM) [21, 22] is available as a comprehensive evaluation of various organ functions and the degree of surgical invasion, indicating surgical risk. POSSUM is reported to be an excellent prognostic system even for colorectal peritonitis [23]. However, because these evaluation methods require a large number of items, they are overly complicated for cases of lower digestive tract perforation requiring emergency surgery and cannot be evaluated appropriately at all facilities. Identification of factors that can be evaluated quickly and easily is therefore necessary. In this study, low PMI and high SOFA score were independent prognostic factors in multivariate logistic regression analysis. PMI is a simple but reliable method of prognostic evaluation similar to SOFA. Body composition has recently been reported as a risk factor or prognostic factor

Table 4 Comparison of postoperative course according to PMI within the survival group

\begin{tabular}{llll}
\hline & Low PMI $(n=21)$ & High PMI $(n=31)$ & $P$-value \\
\hline DIC score & $3(0-6)$ & $2(0-6)$ & 0.2149 \\
DIC, n (\%) & $7(33.33)$ & $8(25.81)$ & 0.5566 \\
Artificial ventilator, n (\%) & $8(38.10)$ & $15(48.39)$ & 0.4634 \\
Ventilator weaning (days) $^{\mathrm{a}}$ & $3(1-9)$ & $3(1-38)$ & 0.4267 \\
Complications 2/3, n (\%) & $7(33.33)$ & $7(22.58)$ & 0.3910 \\
LOS in ICU (days) $^{\mathrm{a}}$ & $4(1-19)$ & $4(1-18)$ & 0.1791 \\
LOS in hospital (days) $^{\mathrm{a}}$ & $29(10-86)$ & $22(10-58)$ & $0.0257^{*}$ \\
\hline
\end{tabular}

${ }^{*} P<0.05$

DIC, disseminated intravascular coagulation; LOS, length of stay; ICU, intensive care unit

a Values are shown as median (range) 
Table 5 Comparison of postoperative multidisciplinary treatment according to PMI within the survival group

\begin{tabular}{llll}
\hline & Low PMI $(n=21)$ & High PMI $(n=31)$ & $P$-value \\
\hline Vasopressor, n (\%) & $7(33.33)$ & $10(32.26)$ & 0.9354 \\
rTM, n (\%) & $10(47.62)$ & $13(41.94)$ & 0.6855 \\
IVIg, n (\%) & $12(57.14)$ & $16(51.61)$ & 0.6947 \\
hATIII, n (\%) & $3(14.29)$ & $5(16.13)$ & 0.8565 \\
PMX, n (\%) & $7(33.33)$ & $8(25.81)$ & 0.5566 \\
\hline
\end{tabular}

rTM recombinant human soluble thrombomodulin, IVlg intravenous human immunoglobulin, hATIII human anti-thrombin III, PMX-DHP polymyxin Bimmobilized fiber column-direct hemoperfusion

for postoperative complications $[3,5,24,25]$. In particular, skeletal muscle mass is considered important [2628]. Among the methods of evaluating body composition that include skeletal muscle mass are bioelectrical impedance analysis (BIA), dual-energy $\mathrm{X}$-ray absorptiometry (DXA), and CT/magnetic resonance imaging using cross-sectional images. BIA and DXA methods show a strong correlation with each other [29], as do the BIA and CT cross-sectional methods [30]. Each has its advantages and disadvantages. However, in the case of emergency diseases and gastrointestinal cancers, the CT method requires no additional examinations and is simple and quick if images from preoperative examinations are used. Furthermore, with CT methods, one method uses total skeletal muscle area at the L3 level and another measures only the psoas muscle area, but the results are reportedly correlated [30]. In the case of emergency diseases, measuring only psoas may be better in terms of simplicity and speed. The skeletal muscle system accounts for about $40 \%$ of the adult body volume, and around $88 \%$ of muscle is protein, which represents $50 \%$ of total protein in the body. The muscles function as a nutrient storage system, playing the role of distributing amino acids to each organ as a biological defense reaction during invasion. However, in patients with sepsis, active nutrition cannot prevent loss of the body protein compartment despite increases in body fat [31]. In addition, inflammatory cytokines such as IL-6 [32] and tumor necrosis factor $\alpha$ [33] promote proteolysis. Therefore, when extravasation results from emergency surgery under conditions of severe infection, a greater original muscle mass is advantageous for tissue repair as a defense reaction, and organ failure can be avoided. Preoperative skeletal muscle mass is a prognostic indicator in lower gastrointestinal perforation. On the other hand, many reports [27,34] have identified the CT attenuation value as a useful index of muscle quality in cancer patients, because the increase in non-contractile tissue including fat in muscles decreases the CT attenuation value. In this study, CT attenuation was not a prognostic indicator. Under pathological conditions such as lower gastrointestinal perforation, where damage to the body is largely caused by the release of inflammatory cytokines, muscle mass is considered important regardless of muscle quality. In addition, none of visceral fat mass, subcutaneous fat mass or the ratio of those two values represented prognostic indicators. Muscle mass was considered more important in the acute phase than fat. Survivors with low PMI tended to have high DIC score, high DIC rate, and high postoperative complication rate, and additionally had significantly longer duration of hospitalization. It has been suggested that if skeletal muscle mass is reduced, later treatment will be difficult even if the patient survives. However, no significant difference in treatment methods was seen between the two survival groups.

Postoperative intensive care is important in lower gastrointestinal perforation. In intensive care, blood purification treatments such as CHDF and PMX-DHP are available, along with thrombomodulin alfa (a genetical recombination) as pharmacotherapy. No specific opinion has been obtained regarding prognostic improvements from these treatment modalities, and no clear criteria for the introduction of blood purification therapy have been established. Preoperative medical interventions for skeletal muscle loss are not possible with lower gastrointestinal perforation. To improve the survival rate, early introduction of aggressive blood purification and medication may be necessary in the muscle loss group. Measuring the psoas muscle area from CT may offer a useful method for patients who are not suffering from shock upon arrival at the hospital and in facilities where CT can be performed immediately anytime, $24 \mathrm{~h}$ a day. In this study, the number of cases was limited because of the single-center design, and the ability to conduct sufficient studies appears limited. To improve the number of cases in the future, multiple-center studies appear necessary. Furthermore, changes in the effects of treatment according to differences in skeletal muscle mass should be accurately examined in prospective studies.

\section{Conclusions}

Decreased psoas muscle mass was independently associated with poor prognosis of lower gastrointestinal perforation. Measurement of psoas muscle area using CT is convenient, quick, and useful for estimating prognosis.

\section{Abbreviations}

APACHE II: Acute Physiology And Chronic Health Evaluation II; AUC: Area under the curve; CHDF: Continuous hemodiafiltration; CT: Computed tomography; hATIII: Human anti-thrombin III; HU: Hounsfield units; IVlg: Intravenous human immunoglobulin; LOS: Length of stay; PMA: Psoas muscle attenuation; PMI: Psoas muscle index; PMX-DHP: Polymyxin Bimmobilized fiber column-direct hemoperfusion; ROC: Receiver operating characteristic; rTM: Recombinant human soluble thrombomodulin;

SATI: Subcutaneous adipose tissue index; SOFA score: Sequential Organ Failure Assessment; VATI: Visceral adipose tissue index; VSR: Visceral-tosubcutaneous fat area ratio 


\section{Acknowledgements}

Not applicable.

\section{Authors' contributions}

HK and EN conceived the study concept and design, analyzed the data and wrote the manuscript. RA, YU and TM collected and analyzed the patient data. CF, SU, KE and KM analyzed the body composition for the patients. MM and $\mathrm{HM}$ revised the draft. All authors read and approved the final manuscript.

\section{Funding}

This research received no specific grant from any funding agency in the public, commercial, or not-for-profit sectors.

\section{Availability of data and materials}

The datasets used and/or analyzed during the current study are available from the corresponding author on reasonable request.

\section{Ethics approval and consent to participate}

This study was approved by the Institutional Review Board for Clinical Research, Tokai University (approval number 18R-303) and written informed consent for surgery and usage of clinical data was obtained from all participants.

\section{Consent for publication}

Not applicable.

\section{Competing interests}

The authors declare that they have no competing interests.

\section{Author details}

'Departments of General and Gastroenterological Surgery, Tokai University Hachioji Hospital, 1838 Ishikawa-machi, Hachioji, Tokyo 192-0032, Japan. ${ }^{2}$ Departments of Radiation Technology, Tokai University Hachioji Hospital, 1838 Ishikawa-machi, Hachioji, Tokyo 192-0032, Japan.

Received: 8 August 2019 Accepted: 21 October 2019 Published online: 28 November 2019

\section{References}

1. Yilmazlar T, Toker S, Zorluoğlu A. Non-traumatic colorectal perforations. Int Surg. 1999:84:155-8.

2. Bielecki K, Kamiński P, Klukowski M. Large bowel perforation: morbidity and mortality. Tech Coloproctol. 2002;6:177-82.

3. Heus C, Bakker N, Verduin WM, Doodeman HJ, Houdijk APJ. Impact of body composition on surgical outcome in rectal cancer patients, a retrospective cohort study. World J Surg. 2019:45:1370-6.

4. Ozoya OO, Siegel EM, Srikumar T, Bloomer AM, DeRenzis A, Shibata D. Quantitative assessment of visceral obesity and postoperative colon cancer outcomes. J Gastrointest Surg. 2017;21:534-42.

5. Liu Y, Guo D, Niu Z, Wang Y, Fu G, Zhou Y, et al. Prediction of the risk of laparoscopy-assisted gastrectomy by comparing visceral fat area and body mass index. Gastroenterol Res Pract. 2018. https://doi.org/10.1155/2018/ 1359626.

6. Hamaguchi Y, Kaido T, Okumura S, Fujimoto Y, Ogawa K, Mori A, et al. Impact of quality as well as quantity of skeletal muscle on outcomes after liver transplantation. Liver Transpl. 2014;20:1413-9.

7. Okumura S, Kaido T, Hamaguchi Y, Fujimoto Y, Masui T, Mizumoto M, et al. Impact of preoperative quality as well as quantity of skeletal muscle on survival after resection of pancreatic cancer. Surgery. 2015;157:1088-98.

8. Knaus WA, Draper EA, Wagner DP, Zimmerman JE. APACHE II: a severity of disease classification system. Crit Care Med. 1985;13(10):818-29.

9. Vincent JL, Moreno R, Takala J, Willatts S, De Mendonça A, Bruining H, et al. The SOFA (Sepsis-related organ failure assessment) score to describe organ dysfunction/failure. On behalf of the working group on Sepsis-related problems of the European Society of Intensive Care Medicine. Intensive Care Med. 1996;22:707-10.

10. Dindo D, Demartines N, Clavien PA. Classification of surgical complications: a new proposal with evaluation in a cohort of 6336 patients and results of a survey. Ann Surg. 2004;240:205-13.
11. Gallagher D, Visser M, De Meersman RE, Sepúlveda D, Baumgartner RN, Pierson RN, et al. Appendicular skeletal muscle mass: effects of age, gender, and ethnicity. J Appl Physiol. 1997;83:229-39.

12. Tan KK, Hong CC, Zhang J, Liu JZ, Sim R. Predictors of outcome following surgery in colonic perforation: an institution's experience over 6 years. J Gastrointest Surg. 2011;15:277-84.

13. Tocaciu S, Thiagarajan J, Maddern GJ, Wichmann MW. Mortality after emergency abdominal surgery in a non-metropolitan Australian Centre. Aust J Rural Health. 2018;26:408-15.

14. Ingraham AM, Cohen ME, Bilimoria KY, Raval MV, Ko CY, Nathens AB, et al. Comparison of 30-day outcomes after emergency general surgery procedures: potential for targeted improvement. Surgery. 2010;148:217-38

15. Komatsu S, Shimomatsuya T, Nakajima M, Amaya H, Kobuchi T, Shiraishi S, et al. Prognostic factors and scoring system for survival in colonic perforation. Hepatogastroenterology. 2005:52:761-4.

16. Horiuchi A, Watanabe Y, Doi T, Sato K, Yukumi S, Yoshida M, et al. Evaluation of prognostic factors and scoring system in colonic perforation. World J Gastroenterol. 2007;13:3228-31.

17. Kriwanek S, Armbruster C, Beckerhinn P, Dittrich K. Prognostic factors for survival in colonic perforation. Int J Color Dis. 1994;9:158-62.

18. Moreno RP, Metnitz PG, Almeida E, Jordan B, Bauer P, Campos RA, et al. SAPS 3 Investigators. SAPS 3--from evaluation of the patient to evaluation of the intensive care unit. Part 2: development of a prognostic model for hospital mortality at ICU admission. Intensive Care Med. 2005 Oct;31:134555.

19. Higgins TL, Teres D, Copes WS, Nathanson BH, Stark M, Kramer AA. Assessing contemporary intensive care unit outcome: an updated mortality probability admission model (MPM0-III). Crit Care Med. 2007;35:827-35.

20. Marshall JC, Cook DJ, Christou NV, Bernard GR, Sprung CL, Sibbald WJ. Multiple organ dysfunction score: a reliable descriptor of a complex clinical outcome. Crit Care Med. 1995:23:1638-52.

21. Copeland GP, Jones D, Walters M. POSSUM: a scoring system for surgical audit. Br J Surg. 1991;78:355-60.

22. Copeland GP, Sagar P, Brennan J, Roberts G, Ward J, Cornford P, et al. Riskadjusted analysis of surgeon performance: a 1-year study. Br J Surg. 1995;82: 408-11.

23. Ishizuka M, Nagata H, Takagi K, Horie T, Kubota K. POSSUM is an optimal system for predicting mortality due to colorectal perforation. Hepatogastroenterology. 2008;55:430-3.

24. Kuritzkes BA, Pappou EP, Kiran RP, Baser O, Fan L, Guo X, et al. Visceral fat area, not body mass index, predicts postoperative 30-day morbidity in patients undergoing colon resection for cancer. Int J Color Dis. 2018;33: 1019-28.

25. Lee KH, Kang BK, Ahn BK. Higher visceral fat area/subcutaneous fat area ratio measured by computed tomography is associated with recurrence and poor survival in patients with mid and low rectal cancers. Int J Color Dis. 2018:33:1303-7.

26. Valero V 3rd, Amini N, Spolverato G, Weiss MJ, Hirose K, Dagher NN, et al. Sarcopenia adversely impacts postoperative complications following resection or transplantation in patients with primary liver tumors. J Gastrointest Surg. 2015;19:272-81.

27. Sueda T, Takahasi H, Nishimura J, Hata T, Matsuda C, Mizushima T, et al. Impact of low muscularity and myosteatosis on long-term outcome after curative colorectal cancer surgery: a propensity score-matched analysis. Dis Colon Rectum. 2018;61:364-74.

28. Herrod PJJ, Boyd-Carson H, Doleman B, Trotter J, Schlichtemeier S, Sathanapally G, et al. Quick and simple; psoas density measurement is an independent predictor of anastomotic leak and other complications after colorectal resection. Tech Coloproctol. 2019;23:129-34.

29. Yeh C, Chen YJ, Lai LY, Jang TR, Chiang J, Chen YY, et al. Bioelectrical impedance analysis in a mathematical model for estimating fat-free mass in multiple segments in elderly Taiwanese males. Int J Gerontol. 2012;6:273-7.

30. Hamaguchi Y, Kaido T, Okumura S, Kobayashi A, Hammad A, Tamai Y, et al. Proposal for new diagnostic criteria for low skeletal muscle mass based on computed tomography imaging in Asian adults. Nutrition. 2016;32:1200-5.

31. Streat SJ, Beddoe AH, Hill GL. Aggressive nutritional support does not prevent protein loss despite fat gain in septic intensive care patients. J Trauma. 1987 Mar;27:262-6.

32. Vincent HK, Raiser SN, Vincent KR. The aging musculoskeletal system and obesity-related considerations with exercise. Ageing Res Rev. 2012;11:361-73. 
33. Lambert CP, Wright NR, Finck BN, Villareal DT. Exercise but not diet-induced weight loss decreases skeletal muscle inflammatory gene expression in frail obese elderly persons. J Appl Physiol (1985). 2008;105:473-8.

34. Hopkins JJ, Reif RL, Bigam DL, Baracos VE, Eurich DT, Sawyer MB. The impact of muscle and adipose tissue on long-term survival in patients with stage I to III colorectal cancer. Dis Colon Rectum. 2019:62:549-60.

\section{Publisher's Note}

Springer Nature remains neutral with regard to jurisdictional claims in published maps and institutional affiliations.

Ready to submit your research? Choose BMC and benefit from:

- fast, convenient online submission

- thorough peer review by experienced researchers in your field

- rapid publication on acceptance

- support for research data, including large and complex data types

- gold Open Access which fosters wider collaboration and increased citations

- maximum visibility for your research: over $100 \mathrm{M}$ website views per year

At BMC, research is always in progress.

Learn more biomedcentral.com/submissions 